DOI: https://doi.org/10.14232/actahisp.2021.0.31-35

\title{
QUATRE POEMES DE SÁNDOR PETŐFI EN VERSIÓ CATALANA INÈDITA
}

\author{
KÁLMÁN FALUBA \\ Universitat Eötvös Loránd de Budapest
}

\begin{abstract}
Resum: A l'inici del 1907 el catalanòfil hongarès Albin Kőrösi demana a Benet Roura Barrios, el seu corresponsal barceloní, trobar traductors per a set poemes de Sándor Petőfi, poeta nacional d'Hongria. Aquest treball repassa el procés de gestació de les versions, de les qual només quatre van arribar a Kőrösi: dues realitzades per À. Guimerà i dues pel poeta valencià Francesc Badenes.

Paraules clau: Albin Kőrösi, Sándor Petőfi, traducció, Àngel Guimerà, Francesc Badenes.
\end{abstract}

Abstract: At the beginning of 1907, the Hungarian Catalanophile Albin Körösi asked Benet Roura Barrios, his Barcelona correspondent, to find translators for seven poems written by Sándor Petófi, the national poet of Hungary. This work reviews the gestation process of the versions, from which only four reached Körösi: two translated by Àngel Guimerà and two by the Valencian poet Francesc Badenes.

Keywords: Albin Kőrösi, Sándor Petőfi, Translation, Àngel Guimerà, Francesc Badenes.

A l'inici del segle XX, Albin Körösi (1860-1936), un dels primers hispanistes hongaresos ${ }^{1}$, es va encarregar de fer traduir al castellà i al català set poemes de Sándor Petőfi (1823-1849), poeta nacional d'Hongria. L'any 1911 dona compte dels resultats de la seva iniciativa a les pàgines 141-158 del volum Petófi a világirodalomban ('Petófi a les lletres universals'). La gairebé totalitat del seu escrit, de quinze pàgines escasses d'extensió, se centra en les versions castellanes de Juan Ruiz Estelrich, publicades a la Revista Contemporánea de Madrid el 15 de maig de 1907, i ofereix en traducció hongaresa l'estudi d'Estelrich que acompanyava els poemes. A les pàgines 155 i 156 Körösi es refereix molt breument a les versions catalanes realitzades a iniciativa seva. Diu: "Per aconseguir les versions catalanes, em vaig adreçar al doctor Benet R. Barrios ${ }^{2}$, amic comprovat, qui manté un contacte permanent amb els cercles literaris i artístics de Barcelona. Vaig enviarli, a ell també, les traduccions en prosa espanyola dels poemes mencionats, però el resultat fou parcial: dels set poemes només dos van trobar traductor. [...] De tota manera, el valor d'aquestes versions queda acrescuda pel fet que es deuen a Àngel Guimerà, el millor dels poetes catalans d'ara, conegut entre nosaltres pel poema L'any mil i el llibret de l'òpera Terra baixa." Les missives adreçades per Barrios a Körösi, conservades a Budapest a

\footnotetext{
${ }^{1}$ Sobre Kőrösi, vegeu Kotlán (1981) i també Faluba (1982).

${ }^{2}$ Sobre Barrios, vegeu Duran Tort (2006). La seva correspondència amb Kőrösi fou buidada per Kotlán (2009).
} 
l'arxiu de les Escoles Pies (Körösi era religiós escolapi), com també documents custodiats al Museu Literari Petőfi (Petőfi Irodami Múzeum) de la mateixa ciutat, matisen aquesta afirmació: en realitat van arribar a les mans de Körösi, a més de les realitzades per Guimerà, dues versions petőfianes més, enllestides pel poeta valencià Francesc Badenes. Abans de fer conèixer les quatre traduccions, reconstruïm el seu procés de gestació tal com es reflecteix a les cartes i postals de Barrios, escrites en castellà, de vegades deficient, $i$ algunes notes de Kőrösi en hongarès.

Trobem la primera referència al projecte, i a les versions literals de Kőrösi, en una postal datada el 16 d'abril de 1907. S'hi diu: "He recibido carta con las traducciones de su poeta nacional. Desde luego que no he de buscar un poeta ripioso, pues para que la traducción sea mala, no vale la pena”. Fidel a aquesta convicció, el 9 de juny escriu, esperançat: "Guimerà quizás se encargará de un par de poesías populares para traducirlas", on "popular" segurament vol dir 'de caire folklòric', com eren la majoria dels poemes seleccionats per Körösi. El tema de les traduccions reapareix el 20 de juny, a propòsit de la publicació de les versions castellanes d'Estelrich, quan Barrios avança un eventual equip traductor, dient: "Las catalanas serán de Guimerà, de un presbítero y del director de Joventut.” Aquest darrer, a qui es farà referència també més avall, fou Lluís Via (1870-1940), poeta i traductor de poesia, fundador i director del setmanari modernista Joventut, publicat entre el febrer de 1900 i la fi de 1906. La identitat del "presbítero", personatge que no torna a figurar en la correspondència, ens és desconeguda. A l'octubre de 1907, annexades a una carta sense datar, arriba la primera collita. Barrios hi diu: "Como ve, incluyo las traducciones hechas por Guimerà; ahora espero las de los otros dos señores." Més endavant afegeix: "Estas traducciones me agradan mucho más que las de Estelrich. No sé cuál será su parecer." El traductor valencià, encara sense nom ni cognom, apareix en una carta en què Barrios, després de consultar amb Guimerà, aclareix uns dubtes que sorgeixen a Körösi en traduir L'any mil del poeta català, poema que sortiria en versió hongaresa al diari Budapesti Hírlap el 25 de desembre de 1907. Barrios hi diu: "He dado un par de poesías de Petőfi (Vd. debe verlo de su ventana) ${ }^{3}$ a un poeta valenciano; a ver si me las traduce." I el valencià les va traduir ben aviat, com ho testimonia la carta de Barrios datada el 12 de gener de 1908: "Tengo el gusto de incluirle las dos traducciones de las poesías de Petőfi al valencià, variedad catalana, cosa que sin duda servirá mejor a Vds., los de esa sociedad admiradora del poeta ${ }^{4}$. El autor es F. Badenes i Dalmau, un laureado poeta valenciano que ahora vive en Barcelona ...”. Al final de la carta Barrios afegeix que Badenes (18591917) és membre del Rat Penat de València i mestre en gai saber. A la mateixa missiva hi trobem una pregunta a què només podia correspondre una resposta negativa: “Recibió Vd. las traducciones hechas por mi amigo-literato (antiguo director de Joventut) Lluís Via? No me ha dicho Vd. nada más.” Hem de lamentar, doncs, la

\footnotetext{
${ }^{3} \mathrm{Al} \cdot$ lusió a l'estàtua del poeta, a la vora del Danubi, ben visible des del convent dels escolapis en què vivia Kőrösi.

${ }^{4}$ Es refereix a la Petófi Társaság ('Associació Petőfiana'), dedicada al culte i difusió de l’obra del poeta.
} 
pèrdua d'altres versions catalanes de poemes de Petőfi, entre elles, probablement, la de Szeptember végén ('A la fi de setembre'), un dels cims de l'obra del poeta.

A continuació oferim les quatre poemes en versió catalana en el mateix ordre en què les trobem en la correspondència Barrios-Körösi: comencem amb les dues de Guimerà i continuem amb les dues de Badenes. Els títols originals en són: Te voltál egyetlen virágom..., Reszket a bokor, mert..., Boldog éjjel..., Eq. a világ amilyen nagy.... La nostra transcripció respecta totes les característiques de l'original.

\section{Tu sigueres ma única flor}

Eras la flor que adorava y so un erm, puig t'has marcit.

Eras mon sol que brillava: desperta que tot es nit.

Eras l'ala que volava: trencada he caygut ferit.

Eras ma sanch que abrusava:

tú ets freda, y mort m’he sentit.

30. 9. 97. trad. Angel Guimerà

\section{Tremola l'abret ...}

Per que s'hi ajoca un aucell com s'estremeix la planta! Per que á ma pensa has volat quin tremolarme l'anima!

Dintre ma pensa ha volat la meva enamorada.

No hi ha altre brillant al mon de mes llums y mes cayres.

Del Danubi’l llit es plé: potser surti de mare. $Y$ no hi caben en mon pit, del amor, les onades.

M'estimas roseret meu?

Jo't vuy ab l'anima!

No t'estiman mes que jo

lo teu pare y ta mare. 
En un temps qu' eram plegats, oh amor, com m'estimavas!

Tot era al cor del istiu: ara es tot l'hivernada!

Que 't beneheixi 'l bon Deu si no m'estimas ara: $y$ 't benheixi mil cops si m'estimas encara.

trad. Angel Guimerà Octubre 1907

\section{Nit feliç}

¡Nit feliç! De m’aymada estich juntet, $\mathrm{y}$ ab ella joguineje al jardinet.

Tot calla; sols del cá es sent la hudolada; en lo cel blaminós

lluhix l'estel hermós

y la lluna argentada.

No serviria yo per fer d'estel;

bé sab Deu que no sempre fora al cel; tot hora estar en ell, no, mo'm plauria, y abaxara seguit pera voret cada nit, sols per voret, aymía.

\section{¡Quán gran es la terra!}

Quán gran es la terra, l'espléndit planeta; y tu, ma estimada, quán eres xiqueta; mes si tu aplegares un jorn à ser mia, enjamay per ella, enjamay yo 't daría.

Tu eres hermós dia; yo, nit endolada que espesa foscuria ne té enmantellada. Si un jorn se fonguesen nostres cors, aymía, ¡Qué aurora més clara per mi brillaría! 
Cap à terra mira, no axís cara à cara;

la teva mirada mon pit jay! cremara;

mes si és que m'estimes, com sabs que voldria,

miram y que 's creme mon pit, vida mia.

Barcelona. Dbre 1907. Fr. Badenes Dalman

\section{Referències bibliogràfiques}

Duran Tort, Carola (2006). Un viatger empedreit. Benet Roura i Barrios, ambaixador de la literatura catalana. Dins: Massot i Muntaner, Josep (coord.). Estudis de Llengua i Literatura Catalanes, vol. LII. Barcelona: Publicacions de l'Abadia de Montserrat. 31-68.

Faluba, Kálmán (1982). Llengua i literatura catalanes a Hongria. Dins: Massot i Muntaner, Josep (coord.). Estudis de Llengua i Literatura Catalanes, vol. V. Barcelona: Publicacions de l'Abadia de Montserrat. 213-221.

Kotlán, Sylvia (2009). Literatura i filologia catalanes reflectides pel mirall deformant de les cartes de B. Roura Barrios enviades a Budapest. Dins: Faluba, Kálmán - Szijj, Ildikó (eds.). Actes del Catorzè Col-loqui Internacional de Llengua i Literatura Catalanes. Budapest (2006), vol. 1. Barcelona: Publicacions de l'Abadia de Montserrat. 283-294.

Kotlán, Sylvia (1981). Prehistòria de la catalanística a Hongria. Lluc, 699. 26-27. 